Психология. Журнал Высшей школы экономики,

2017. T. 14. № 1. C. 105-122. DOI: 10.17323/1813-8918.2017.1.105.122.

\title{
МЕТАИНДИВИДУАЛЬНАЯ МОДЕЛЬ ДЕСТРУКТИВНОСТИ. СООБЩЕНИЕ 1
}

\author{
Л.Я. ДОРФМАН ${ }^{\mathrm{a}}$ К.В. ЗЛОКАЗОВ
}

${ }^{a}$ Пермский государственный институт культуры, 614000, Россия, Пермь, ул. Газеты Звезда, д. 18

${ }^{\text {b } У р а л ь с к и и ̆ ~ ю р и д и ч е с к и и ̆ ~ и н с т и т у т, ~ 620137, ~ Р о с с и я, ~ Е к а т е р и н б у р г, ~ у л . ~ К о м с о м о л ь с к а я, ~ д . ~} 21$

\section{Резюме}

Предложена идея о гетерогенной природе деструктивности. Данная идея косвенно поддерживается наличием у деструктивности множества частных форм. Однако они отделены друг от друга, и вопрос их общего корня остается открытым. Ситуация усугубляется тем, что имеющиеся одномерные вопросники осложняют психометрическую перспективу многоаспектных эмпирических исследований деструкции с единых позиций, в то время как собственно многомерные (многофакторные) вопросники деструкции не разработаны. Показано, что с теоретико-эмпирических позиций понятие деструктивности (или деструкции) можно употреблять в узком и широком значении. В узком значении деструктивность есть склонность личности к деформациям с негативными коннотациями, в пределе - к поражению, разрушению, психологическому распаду себя и людей ближнего окружения. В широком значении понятие деструктивности описывает также смежные явления, например агрессию, психическую травму, девиантность. Эти вопросы исследуются в статье в трех направлениях. Во-первых, анализу подвергаются частные формы деструктивности. Вовторых, освещаются инструменты ее измерения. В-третьих, предпринята попытка обозначить перспективу изучения деструктивности с позиций интегративного подхода.

Ключевые слова: деструктивность, деформация, холон, гетерогенность, вопросники деструктивности, интегративный подход.

\section{Введение}

С позиций концепции метаиндивидуального мира разработан ряд частных моделей, например Я-концепции (Дорфман, 2004), креативности (Дорфман, 2007), эмоций (Дорфман, 1997), эмоциональных предпочтений (Дорфман, 1997; Дорфман, Токарева, 2013), дисциплинированности (Дорфман, Лядов, 2015). Вместе с тем до сих пор вне поля метаиндивидуального подхода остается такой социально важный феномен, как деструктивность.

В настоящей статье предпринята попытка в определенной степени восполнить образовавшийся здесь пробел и наметить теоретико-эмпирические контуры метаиндивидуальной модели деструктивности.

А.В. Юревич и Д.В. Ушаков (2012) изучали динамику психологического состояния российского 
общества в 1981-2011 гг. по экспертным оценкам. Они установили негативную динамику по подавляющему большинству показателей. К 2011 г. в психологической атмосфере нашего общества наблюдался значительный рост агрессивности, враждебности, грубости, жестокости, злобы, наглости, насилия, ненависти, хамства. Bce эти характеристики, в той или иной степени, относятся к области деструктивности. Ее наличие свидетельствует о психологическом неблагополучии российского общества. Для изменения этой ситуации и наступления позитивного перелома углубленные исследования деструктивности встают на повестку дня и востребованы нашим обществом.

Конечно, как отмечают Юревич и Ушаков (2012), общество состоит из конкретных индивидов и различных социальных групп, психологическая атмосфера - это обобщенная, не учитывающая индивидуальных различий и других нюансов характеристика общества. Одни его представители подвержены деструкции, другие - нет. Мы будем исследовать деструктивность как явление (а не ее распространенность в социуме) на личностно-межличностном уровне. Конечно, это абстракция, но широко распространенная и принятая в эмпирической психологии (см.: Дорфман, 2012).

Собственно в исследовательском и психолого-содержательном плане отметим результаты зарубежных исследований, которые приводят к идее гетерогенной природы деструктивности (см.: Дорфман, Злоказов, 2016a, 2016б). Вместе с тем эта идея не оформлена концептуально. С дру- гой стороны, применяемые вопросники, как правило, являются односторонними в том смысле, что они не учитывают множественность факторов, обусловливающих деструктивность. Одной из причин этого является отсутствие концепций деструктивности, принимающих во внимание их разнородность (гетерогенность). Так возникает фундаментальное противоречие между разрозненными теоретическими представлениями о деструкции и отсутствием подходов, объединяющих их в единую концепцию. Ситуация усугубляется тем, что одномерные вопросники закрывают психометрическую перспективу многоаспектных эмпирических исследований деструкции с единых позиций, в то время как собственно многомерные (многофакторные) вопросники деструкции не разработаны.

Преодолеть указанные выше противоречия можно при концептуальном оформлении деструктивности в гетерогенном ключе с единых позиций и разработке принципиально новых средств их измерения на многофакторной основе. Эти вопросы исследуются в настоящей статье в трех направлениях. Во-первых, анализу подвергаются частные формы деструктивности и инструментов ее измерения. Во-вторых, предпринята попытка обозначить перспективу изучения деструктивности с позиций интегративного подхода. На этой основе, в-третьих, предложены контуры метаиндивидуальной модели негативного деструктивного мира, преодолевающей в определенной степени разрозненные представления о деструктивности. 


\section{Понятие деструктивности}

В психологической науке понятие деструктивности пересекается в той или иной степени с рядом смежных понятий, и потому порой возникает впечатление понятийной неразберихи в этом вопросе. Девиантность, агрессия, жестокость, насилие, а также травма, посттравматический стресс, фрустрация, депрессия лишь немногие понятия, с которыми деструктивность в каких-то аспектах пересекается. В ряд смежных с деструктивностью понятий вписываются также месть, ненависть, зависть, ревность. Тема понятийных пересечений деструктивности со смежными феноменами нуждается в отдельном анализе и выходит за рамки задач настоящей статьи. Но как понимать собственно деструктивность?

Условимся подвергать анализу деструктивность в рамках эмпирической парадигмы, включая применение эмпирически верифицируемых теорий и понятий, операционализации, измерений и т.п. Эмпирическая традиция находится в оппозиции к априорной традиции (Дорфман, 2012), поэтому за рамками нашего анализа остаются те априорные понятия деструктивности, перспектива конвертации которых в эмпирические понятия неясна.

$\mathrm{C}$ теоретико-эмпирических позиций понятие деструктивности (или деструкции) можно употреблять в узком и широком значении.

В узком значении деструктивность есть склонность личности к деформациям с негативными коннотациями (в пределе - к поражению, разрушению, распаду) себя и людей ближнего окружения. В результате деструкции человек враждебно относится к себе, другим людям, предметам, вещам, животным, событиям и т.п. (Меннингер, 2001; Фромм, 2004; Baumeister, 1997; Baumeister, Scher, 1988). В узком значении деструктивность - это самостоятельное понятие, которое не сводится к другим, пусть даже близким, неважно, обнаруживается или не обнаруживается связь деструкции с ними.

В широком значении понятие деструктивности захватывает также смежные понятия. Эта традиция идет от 3. Фрейда (Freud, 1933/ 1965). Он выделял (1) агрессию, следующую за фрустрацией: человек разрушает объекты, которые служат источником его негативных чувств; (2) защитная агрессия призвана отдалить деструктивную опасность извне. К деструктивности были отнесены также (3) садизм: деструкция объекта, приводящая к сексуальному удовольствию; (4) нарциссическая деструктивность как результат инстинкта влечения к смерти; (5) мазохизм: склонность получать удовольствие, испытывая унижения, мучения или применяя насилие (см.: Дорфман, Злоказов, 2016а). Практика расширенного понимания деструктивности продолжается и в последние годы (например: Воронцова и др., 2014). В связи с этим у деструктивности эмпирически обнаруживается множество форм и разнообразный состав. В зарубежных исследованиях, например, фигурирует деструктивная сторона психической травмы (посттравматического стресса) (Ehlers et al., 1998, 2000; Feeny et al., 2000), депрессии (Armey et al., 2015; Gilbert, Allan, 1998; 
Goldstein, Willner, 2002; Taylor et al., 2011), оскорблений (Muller et al., 2000; Taussig, Litrownik, 1997), девиантности (Krasikova et al., 2013; Lipman-Blumen, 2005), психических расстройств (Morey, 1988; Reich, 1989; Samuel, Widiger, 2008). Деструктивную сторону имеют также лидерство (Ashforth, 1994; Krasikova et al., 2013; Reed, Bullis, 2009) и креативность (Knauss, 1999; Minocha et al., 2014).

В широком значении деструктивность - это понятие с размытыми границами, в котором можно выделить, по меньшей мере, три стороны.

Во-первых, деструктивность распространяется и сливается с родственными (близкими) понятиями. Деструкция в рамках агрессии или деструкция в рамках травмы - это примеры деструктивности с размытыми границами, поскольку деструкции обнаруживаются не сами по себе, а в агрессии или травме.

Во-вторых, деструктивность в смежном явлении приобретает частный характер. Скажем, признаки деструктивности психической травмы ограничиваются именно травмой и, как правило, не переносятся на деструктивную сторону руководства и лидерства. Деструктивность психической травмы выражается в том, что жертва утрачивает чувства субъектности и автономности, исчезает желание контролировать и поддерживать самоидентичность, свободно выражать свою волю, делать свободные выборы. Психические повреждения Я-концепции приводят к утрате самоидентичности. А. Элерс с соавт. (Ehlers et al., 1998, 2000) обозначают этот феномен термином «ментальное поражение». Его появление наиболее вероятно в ситуациях, когда жертва лишена возможности избегать угроз и жестоких обращений людей. В результате она испытывает беспомощность, бессилие, а ситуация выходит из-под ее контроля (Frederick, 1986; Herman, 1992). Негативные восприятия событий обостряют нежелательные посттравматические реакции и стресс (Dunmore et al., 1999; Ehlers et al., 1998; Horowitz, 1990; Van der Kolk et al., 1996). B сравнении с деструктивностью психической травмы, у деструктивной стороны лидерства и руководства иные особенности: злонамеренность, оскорбления, элементы тирании, запугивание, стремление наносить вред подчиненным (Einarsen et al., 2007; Krasikova et al., 2013). Деструктивность имеет свою специфику применительно также к девиантности, психическим расстройствам, креативности. Специфика деструктивности придает ее отдельным формам частный характер, поскольку рамками отдельных явлений главным образом она и ограничивается.

В-третьих, у деструктивности с размытыми границами есть оборотная сторона. Явления, в которые вплетается деструкция, оказываются двойственными, потому что на их собственные признаки накладываются специфические особенности деструкции. Скажем, агрессия может быть деструктивной и не деструктивной (Шестакова, 2011). В свою очередь, деструктивность может принимать как агрессивный, так и неагрессивный характер. В одних случаях оскорбления (деструктивность) могут быть агрессивными. В иных случаях оскорбления (деструктивность) могут проявляться в неприличных 
высказываниях о человеке, но в вежливой форме, без агрессии. Очевидно, что деструктивность не является родовым признаком агрессии, а агрессия - родовым признаком деструктивности. Деструкция и агрессия пересекаются, но частично, не сливаясь. При этом агрессия, в которую вплетается деструкция, зачастую приобретает двойственный характер.

\section{Инструменты измерения деструкции}

Легко заметить, что концептуальные представления о деструктивности оказываются весьма пестрыми (см. выше). Это обстоятельство получает свое неизбежное продолжение в инструментах измерения деструкции.

Некоторая часть зарубежных вопросников деструкции разрабатывалась с позиций Диагностического и статистического руководства расстройств психики, изданного Американской психиатрической ассоциацией (прежде всего, Diagnostic and Statistical Manual of Mental Disorders, DSM-III-R) в 1987 г. Враждебное отношение человека к себе рассматривалось как личностное расстройство. Хотя традиция рассмотрения деструктивности как личностного расстройства в той или иной степени продолжается, эти же вопросники применяются для изучения деструктивности психически здоровых людей (Baumeister, 1997; Baumeister, Scher, 1988; Briones et al., 2007; Hawton et al., 2002; Minocha et al., 2014; Reed, Bullis, 2009; Schill, 1990; Wei, Ku, 2007).
Вопросник диагностики личности (Hyler, Rieder, 1987) разработан с позиций DSM-III-R и включает шкалы, направленные на измерение 13 личностных расстройств, в том числе шкалу самопоражения (самодеструкции). Эта шкала определяет склонность личности испытывать неприязнь и быть придирчивой к себе, бояться успеха и счастья. Она же используется в исследованиях самопоражения у психически здоровых людей.

Популярной является шкала самопоражающей личности (Schill, 1990). В ее основу также положен DSM-III-R, причем личность рассматривается как жертва внешних обстоятельств. Данная шкала диагностирует самопоражение личности по восьми критериям: (1) личность выбирает людей, которые ее оскорбляют или вызывают разочарование, или ситуации, приводящие к неудаче, даже когда можно сделать иной, благоприятный выбор; (2) личность отвергает или не воздает должное людям, которые пытаются оказать ей поддержку; (3) личность отвечает на позитивные события чувством вины или поведением, приносящим ей боль; (4) личность вызывает гнев или отвержение других людей и потому чувствует себя уязвленной, оскорбленной или униженной; (5) личность отвергает возможности удовольствий или с неохотой принимает их; (6) личность терпит фиаско, решая важные задачи, хотя способна их решить; (7) личность не интересуется людьми или отвергает тех, кто относится к ней благожелательно; (8) личность склонна к чрезмерному самопожертвованию в отношении 
людей, которые не просят ее об этом. Т. Шилл (Schill, 1990) подчеркивает, что его шкала не диагностирует и не предсказывает самопоражение личности в ответ на физические, сексуальные или психологические оскорбления. Данная шкала неприменима также к лицам, которые находятся в состоянии депрессии.

Другая часть шкал поражения (деструкции) не основывается на американском Диагностическом и статистическом руководстве расстройств психики, а опирается на житейские наблюдения. Шкала тирании, которую предложил Б. Эшфорт (Ashforth, 1994), создавалась путем контент-анализа ответов студентов в более раннем исследовании. Они проходили курс обучения предпринимательской деятельности и описывали ситуации, в которых их руководитель важничал, разыгрывая из себя повелителя и демонстрируя свою власть. Затем Эшфорт учел результаты контент-анализа ответов студентов при построении шкалы тирании, основанной на оценках двумя подчиненными их руководителей. Довольно высокая согласованность оценок руководителя подчиненными свидетельствует о надежности данной шкалы. Она включает шесть измерений: (1) произвол, стремление к величию и расширению своей власти, (2) унижение людей, (3) недостаточная забота о них, (4) принуждение в ситуациях разрешения конфликтов, (5) игнорирование инициатив, исходящих от подчиненных, (6) практика необусловленных наказаний. Эти измерения тирании имели приемлемую конвергентную и дискриминантную валидность. Корреляции между ними были значимыми и высокими. При эксплораторном факторном анализе пункты измерений после ротации или распадались на шесть факторов, или входили в один и тот же фактор. По мнению Эшфорта (Ibid.), 6-факторное решение свидетельствует о многомерности конструкта тирании, а 1-факторное решение - о связности этих измерений.

Впрочем, создание шкал деструктивности, основанных на житейских наблюдениях, не совсем обычная практика конструирования инструментов измерения. «Нормальная» практика, как известно, состоит в требовании конструктной валидности шкал, вопросников, тестов и т.п.

К. Келли с соавт. (Kelley et al., $1985)$ предложили шкалу самодеструктивности. В ее основе лежит идея о том, что стремление к немедленному эмоциональному удовольствию при росте вероятности отдаленных негативных последствий приводит человека к самодеструкции. Предпосылки этой шкалы просматриваются в концепции самодеструкции Р. Баумейстера и С. Шера (Baumeister, Scher, 1988). Келли с coaвт. (Kelley et al., 1985) выделили четыре склонности самодеструктивной личности: беспечность, пренебрежительное отношение к своему здоровью, непослушание, изъяны в планировании собственных действий. В конечном итоге авторы приходят к мысли о том, что их шкала включает пункты, сближающие ее с конструктами поиска ощущений, нейротизма и импульсивности. Тестируя шкалу самодеструктивности Келли с соавт. (Ibid.), M. Шарп и Т. Шилл (Sharp, Schill, 1995) приводят эмпирические 
свидетельства о том, что она соотносится с импульсивностью, пониженной критичностью, стремлением к немедленному получению удовольствия.

С позиции эволюционного подхода к депрессии и теории психологических последствий социального положения человека (см. обзор: Taylor et al., 2011) Э. Гриффитс с соавт. (Griffiths et al., 2015) разработали единую шкалу поражения и задержанного порыва. Поражение концептуализируется как безуспешная попытка социальной борьбы, а задержанный порыв - как блокированный мотив избегания создающих отвращение ситуаций. Первоначально конструкты поражения и задержанного порыва рассматривались по отдельности. Соответственно шкалы, направленные на их измерение, также были раздельными (Gilbert, Allan, 1998). В последнее время появились теории и исследования, которые обосновывают объединение этих конструктов (Sturman, 2011; Taylor et al., 2009). Теоретически допускается, что и поражение, и задержанный порыв обусловлены вынужденной субординацией и проявляются в депрессивных симптомах (Sturman et al., 2015). П. Тейлор с coaвт. (Taylor et al., 2011) предположили, что поражение и задержанный порыв, создаваемые ситуациями отвращения, основаны на общем механизме самоподкрепления. Благодаря ему поражение и задержанный порыв влияют друг на друга, сосуществуют, и нет оснований их разделять. В связи с этим Э. Гриффитс с соавт. (Griffiths et al., 2015) предложили короткую единую шкалу поражения и задержанного порыва. Она имеет высокие показатели надежности. Результаты эксплораторного и конфирматорного факторного анализа показали, что однофакторное решение наиболее пригодно для отображения пунктов этого объединенного конструкта. Это означает, что выражающая его шкала обладает конструктной валидностью. Кроме того, было установлено, что показатель этой шкалы значимо коррелирует с показателями депрессии и безысходности и в то же время не сводится к ним (критериальная валидность). По данным ретеста, единая шкала поражения и задержанного порыва характеризуется стабильностью.

\section{Проблема и перспектива ее изучения}

\section{Колллизия спещифичного и общего в деструктивности}

Представленный выше краткий обзор литературы свидетельствует о том, что деструктивность изучается эмпирически не столько сама по себе, сколько в связи с исследованием психической травмы, депрессии, оскорблений, девиантности, лидерства, креативности и т.п. Концептуально, впрочем, не совсем понятно, специфика ли явления накладывает определенный отпечаток на деструктивность или, наоборот, деструктивность как самостоятельное явление неодинаково выражается в разных феноменах. Так возникает коллизия специфичного и общего в деструктивности.

Наименее очевидным является вопрос о том, существует ли деструктивность как общий и самостоятельный 
феномен, перекрывающий специфичность его частных форм. Пестрота концептуальных моделей отражает разрозненные представления о них. Им не хватает, однако, широты, общей картины, преодолевающей односторонние взгляды на деструктивность отдельных явлений. Как общий (неспецифический) феномен деструктивность в минимальной степени осмыслена и изучена.

Существующие инструменты измерения деструктивности также несут на себе печать избыточной специфичности. Они обладают конструктной валидностью применительно к концепциям, на основе которых создавались, надежностью и другими убедительными психометрическими параметрами. Но они не предназначены для измерений общей (неспецифической) деструктивности. Более того, инструменты измерения деструкции в границах одних явлений, как правило, невозможно перенести и применить в исследованиях деструкции в других явлениях.

В конечном итоге эмпирическое изучение общей (неспецифической) деструктивности сдерживается отсутствием необходимых концептуальных предпосылок и инструментов измерения, обладающих соответствующей конструктной валидностью. Вместе с тем их разработка обещает наметить новое направление в исследованиях деструктивности.

\section{Интегративный подход}

Мы видим перспективу решения проблемы общей деструктивности в интегративном подходе (см., например: Дробышева-Разумовская и др.,
2015; Петровский, 1997, 2009). Целостный (включая системный) подход образует методолого-теоретический ориентир интегративных исследований (например: Абульханова, 2012; Вяткин, 2015; Мерлин, 1986; Петровский, 1981, 2013; Петровский, Старовойтенко, 2012; Рубинштейн, 2003).

Интегративный тренд намечается в исследованиях деструктивного лидерства: осознается востребованность построения объединенной теории, которая позволила бы обозначить его общие базовые посылки (Krasikova et al., 2013; Tepper, 2007). Пока, однако, эта идея заужена, распространяется лишь на область деструктивного лидерства. Общее же ви́дение деструктивности сдерживается рядом нерешенных, прежде всего концептуальных, проблем. Их своевременное изучение с интегративных позиций позволит существенно уменьшить имеющиеся пробелы в этой сфере и преодолеть разрывы между исследованиями частных форм деструктивности в разных явлениях. Поиск интегративной базы - это новый методологический поворот в исследованиях деструктивности. Он позволит получить новые знания о ней.

Как достичь общего (интегративного) понимания деструктивности? Предлагается данную задачу разложить на три уровня. Во-первых, в анализ включается теория, описывающая фрагмент психологической реальности, который шире сферы деструктивности (уровень А). Во-вторых, анализ захватывает общую деструктивность (уровень Б). В-третьих, в анализ вовлекаются частные формы деструктивности (уровень 
В). Следует раскрыть характер отношений уровня Б с уровнями А и В. Для этого обратимся к холону, одному из понятий, усвоенных системным подходом (см., например: Дорфман, 2000, 2006, 2012; Stamps, 1980).

\section{Холон}

Как известно, холономность есть не холизм и не атомизм, но их интеграция через совмещение целого и части в одном и том же явлении. Вопрос о характере их совмещения представляет собой главную «изюминку» холона. Холон раскрывает искомое явление одновременно как целое и как часть, но в разных отношениях. Искомое явление (уровень Б) есть часть по отношению к более широкому явлению (уровень А) и целое по отношению к своим частям (уровень В). Холон объединяет в едином анализе отношений всю триаду уровней Б, А и В, искомое же явление (уровень Б) берется в паре и с уровнем А, и с уровнем В.

Следующие базовые особенности характеризуют холон. Во-первых, искомое явление соотносится с уровнем А как часть и с уровнем В как целое. Во-вторых, искомое явление как часть не входит в уровень А, а как целое не входит в уровень В. В-третьих, искомое явление есть одновременно часть и целое на одном и том же уровне Б. Причем они расходятся и прямо не соотносятся друг с другом. В-четвертых, в холоне целое и часть реляционны и дополнительны. Вненахождение целого и его частей представляет собой фундаментальное положение, которым холономный подход отличается от холизма и атомизма.

Многие наблюдаемые феномены устроены по принципу холона. Так, язык устроен холономически. Фонемы выступают как целое по отношению к буквам и как часть по отношению к словам; фразы есть целое по отношению к словам и являются частью предложения и т.д. Далее мы расширим холономный взгляд на отношения целого и части, распространив его на сходные отношения общего и частного (см.: Дорфман, 2014). Холономный подход будет применяться скорее эпистемологически, а не онтологически, т.е. как общая схема исследования деструктивности.

\section{Приниип холономности в исследованиях деструктивности}

Следуя принципу холономности, можно обозначить два относительно независимых направления исследований деструктивности, причем в режиме их дополнительности.

К первому направлению («снизу») отнесем исследования от частных форм деструктивности к ее общему представлению, от низких степени обобщения и уровня абстракции к более высоким и перекрывающим разобщенность частных форм. Отношения частного и общего в деструктивности вписываются в подход Канта («Критика чистого разума»): частные формы деструктивности существуют вне и внутри общего. В последнем случае появляется понимание деструкции как многокачественного и разнокачественного явления. Общая деструктивность - 
это интегративное качество, разнородное и гетерогенное в силу наличия у него множества частных форм.

Ко второму направлению («сверху») отнесем исследования, которые идут от теории, описывающей фрагмент реальности, который шире сферы деструктивности. Данное направление наименее разработано и понятно. В первом приближении заметим, что это не обратное движение к частным формам деструктивности, которые включаются в исследования «снизу». Это ход к деструктивности как части более широкой реальности. Деструктивность «сверху» и деструктивность «снизу» расходятся и прямо не соотносятся друг с другом, поскольку происходят из разных источников. В то же время деструктивность «сверху» и деструктивность «снизу» предположительно сосуществуют и сопоставимы по степени обобщения и уровню абстракции. Не исключено, что они связаны друг с другом.

В данном пункте анализа возникает несколько задач. Во-первых, более широкую, чем область деструктивности, теорию следует верифицировать (теоретически и эмпирически) на предмет ее релевантности деструктивным следствиям. Не всякая общая теория приводит к выявлению деструктивных паттернов. Во-вторых, как часть более широкой реальности, деструктивность возникает, скорее всего, как неспецифичное и более широкое по масштабу явление, чем частные формы деструктивности и даже общая деструктивность, создаваемая на их основе в исследованиях «снизу». В самом деле, появление деструктивности «сверху» не может не страдать избыточной абстрактностью. В-третьих, избыточную абстрактность исследований деструктивности «сверху» можно преодолевать, обращаясь к результатам исследований деструктивности «снизу». Без их поддержки исследования деструктивности «сверху» вряд ли будут продуктивными в теоретикоэмпирическом плане.

Далее, в сообщении 2, предпринята попытка развить исследования деструктивности «сверху» с позиций концепции метаиндивидуального мира как варианта полисистемного взгляда на жизненный мир личности (Дорфман, 2016; Dorfman, Barashkova, 2016).

\section{Заключение}

Понятие деструктивности (или деструкции) можно употреблять в узком и широком значении. В узком значении деструктивность есть склонность личности к деформациям с негативными коннотациями, в пределе - к поражению, разрушению, психологическому распаду себя и людей ближнего окружения. В широком значении понятие деструктивности описывает также смежные явления, например агрессию, психическую травму, девиантность. Ситуация усугубляется тем, что имеющиеся одномерные вопросники осложняют психометрическую перспективу многоаспектных эмпирических исследований деструкции с единых позиций, в то время как собственно многомерные (многофакторные) вопросники деструкции не разработаны.

Обзор литературы свидетельствует о том, что деструктивность изуча- 
ется эмпирически не столько сама по себе, сколько касается психической травмы, депрессии, оскорблений, девиантности, лидерства, креативности и т.п. Концептуально, однако, не совсем понятно, специфика ли явления накладывает определенный отпечаток на деструктивность или, наоборот, деструктивность как самостоятельное явление неодинаково выражается в разных феноменах. Так возникает коллизия специфичного и общего (неспецифичного) в деструктивности. Наименее очевидным является вопрос о том, существует ли деструктивность как общий и самостоятельный феномен, перекрывающий специфичность его частных форм. Пестрота концептуальных моделей отражает разрозненные представления о деструкции. Им не хватает, однако, общей картины, преодолевающей односторонние взгляды на деструкцию отдельных явлений. Как общий (неспецифический) феномен деструктивность в наименьшей степени осмыслена и изучена. В конечном итоге эмпири- ческое изучение общей (неспецифической) деструктивности сдерживается отсутствием необходимых концептуальных предпосылок и инструментов измерения, обладающих соответствующей конструктной валидностью. Вместе с тем их разработка обещает наметить новое направление в исследованиях деструктивности.

Намечена перспектива решения проблемы общей деструктивности с позиций интегративного подхода. Предлагается данную задачу разложить на три уровня анализа. Во-первых, в анализ включается теория, описывающая фрагмент психологической реальности, который шире сферы деструктивности (уровень А). Во-вторых, анализ захватывает общую деструктивность (уровень Б). В-третьих, в анализ вовлекаются частные формы деструктивности (уровень В). Следует раскрыть характер отношений уровня Б с уровнями А и В. Для этого привлекается идея холона, одного из понятий, усвоенных системным подходом.

\section{Литература}

Абульханова, К. А. (2012). Развитие психологии в системе комплексного человекознания (ч. 1). М.: Изд-во Институт психологии РАН.

Воронцова, М. В., Макаров, В. Е., Бюндюгова, Т. В. (2014). Теория деструктивности. Таганрог: Изд. А.Н. Ступин.

Вяткин, Б. А. (ред.). (2015). Индивидуальность растущего человека в условиях современной школь. Пермь: Пермский национальный исследовательский политехнический университет.

Дорфман, Л. Я. (1997). Эмоции в искусстве: теоретические подходы и эмпирические исследования. М.: Смысл.

Дорфман, Л. Я. (2000). Проблема целого и части в зарубежных системных исследованиях. Вестник Пермского государственного педагогического университета. Серия 1. Психология, 1-2, 114-122. Дорфман, Л. Я. (2004). Я-концепция: дифференциация и интеграция. В кн. Л. Я. Дорфман (ред.), Интегральная индивидуальность, Я-концепщия, личность (с. 96-123). М.: Смысл. 
Дорфман, Л. Я. (2006). Концепция метаиндивидуального мира: современное состояние. Психология. Журнал Высшей школь экономики, 3(3), 3-34.

Дорфман, Л. Я. (2007). Метаиндивидуальная и полимодальная модели креативности. В кн. В. М. Петров, А. В. Харуто (ред.), Информация, время, творчество (с. 73-79). М.: Государственный институт искусствознания / Московская государственная консерватория им. П.И. Чайковского.

Дорфман, Л. Я. (2012). Эмпирическая парадигма в психологической науке. В кн. А. Л. Журавлев, Т. В. Корнилова, А. В. Юревич (ред.), Парадигмы в психологии: науковедческий анализ (с. 335-379). М.: Изд-во Институт психологии РАН.

Дорфман, Л. Я. (2014). Каузальный плюрализм и психология (окончание). Мир психологии, $4(80), 230-246$.

Дорфман, Л. Я. (2016). Каузальный плюрализм и холизм в концепции метаиндивидуального мира. Психология. Журнал Высшей школь экономики, 13(1), 98-136.

Дорфман, Л. Я., Злоказов, К. В. (2016а). Поражение и деструкция и их исследование в зарубежной психологии. Сообщение 1. Вестник Южно-Уральского государственного университета. Серия: Психология, 9(1), 5-16.

Дорфман, Л. Я., Злоказов, К. В. (2016б). Поражение и деструкция и их исследование в зарубежной психологии. Сообщение 2. Вестник Южно-Уральского государственного университета. Серия: Психология, 9(2), 5-13.

Дорфман, Л. Я., Лядов, В. Н. (2015). Метаиндивидуальная модель дисциплинированности (на материале исследования курсантов военного вуза МВД). Вестник Южно-Уральского государственного университета. Серия: Психология, 8(1), 17-28.

Дорфман, Л. Я., Токарева, Г. В. (2013). Эмоциональные предпочтения и полимодальное Я музыканта-исполнителя. Филология и культура. Philology and Culture, 1(31), 235-241.

Дробышева-Разумовская, Л. И., Дорфман, Л. Я, Вяткин, Б. А., Петров, В. М., Зубарева, Н. Б. (2015). Об интегративной перспективе в гуманитарных науках. Интегративная перспектива в гуманитарных науках, 1, 10-20.

Кант, И. (2006). Критика чистого разума. М.: Эксмо.

Меннингер, К. (2001). Война с самим собой. М.: ЭКСМО-Пресс.

Мерлин, В. С. (1986). Очерк интегрального исследования индивидуальности. М.: Педагогика.

Петровский, В. А. (1981). К пониманию личности в психологии. Вопросы психологии, 2, 40-46.

Петровский, В. А. (1997). Очерк теории свободной причинности. В кн. Д. А. Леонтьев, В. Г. Щур (ред.), Психология с человеческим лицом: гуманистическая перспектива в постсоветской психологии (с. 124-144). М.: Смысл.

Петровский, В. А. (2009). Логика «Я»: персонологическая перспектива. Самара: Изд-во САМГУ. Петровский, В. А. (2013). «Я» в персонологической перспективе. М.: Издательский дом НИУ ВШЭ. Петровский, В. А., Старовойтенко, Е. Б. (2012). Наука личности: четыре проекта общей персонологии. Психология. Журнал Высшей школы экономики, 9(1), 21-39.

Рубинштейн, С. Л. (2003). Бытие и сознание. Человек и мир. СПб.: Питер.

Фромм, Э. (2004). Анатомия человеческой деструктивности. М.: АСТ.

Шестакова, Е. Г. (2011). Агрессивность в структуре личности: интегративный подход (Кандидатская диссертация, Пермский государственный институт искусства и культуры, Пермь).

Юревич, А. В., Ушаков, Д. В. (2012). Экспертная оценка динамики психологического состояния российского общества: 1981-2011 гг. Вестник Российской академии наук, 82(10), 930-937.

Ссылки на зарубежные источники см. в разделе References после англоязычного блока. 


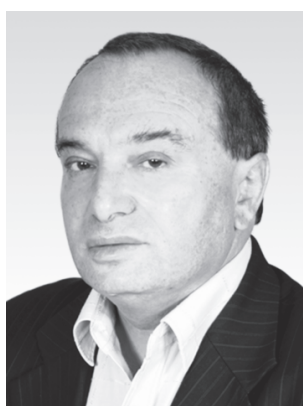

Дорфман Леонид Яковлевич - заведующий кафедрой психологии и педагогики, Пермский государственный институт культуры, доктор психологических наук, профессор.

Сфера научных интересов: индивидуальность, деструктивность, креативность.

Контакты: dorfman07@yandex.ru

Злоказов Кирилл Витальевич - начальник кафедры психологии служебной деятельности и педагогики, Уральский юридический институт, кандидат психологических наук, доцент.

Сфера научных интересов: личность, деструктивное поведение, криминальная идентичность.

Контакты: zkrivit@yandex.ru

\title{
A Meta-Individual Model of Destructive Patterns. Report 1
}

\author{
Leonid Ya. Dorfman ${ }^{\mathrm{a}}$, Kyrill V. Zlokazov ${ }^{\mathrm{b}}$
}

${ }^{a}$ Perm State Institute of Culture, 18 Gazeta Zvezda Str., Perm, 614000, Russian Federation

${ }^{a}$ Ural Institute of Law, 21 Korepina Str., Ekaterinburg, 620017, Russian Federarion

\begin{abstract}
The article presents a common view on destructivity (defeat) and overcomes the hampering effects of fragmentation of destructivity that still dominates psychology. Isolated views on destructive patterns exist due to their partition among trauma, depression, aggression, violence, abuse, and the like. The question of how a composition of destructive patterns appears is still unanswered. This matter is salient but least understandable from the integrative and systems viewpoint. Currently this is complicated by respective questionnaires that rely on partial theories, which obscure the multidimensional view on destructivity. Yet multidimensional questionnaires are not explored and beyond empirical studies. It is shown that there are two definitions of the notion "destructivity" (or "defeat"), which are the narrow and the broad. In a narrow sense, the destructivity consists of a personal disposition to distortion with negative connotations within the limits of defeat, damage, and breakdown of oneself and/or close others. In a broad sense, the described destructive patterns are also related to such phenomena as aggression, psychic trauma, and deviance. These issues are analyzed in three aspects. Firstly, particular destructive patterns are highlighted. Secondly, questionnaires intended to measure them are
\end{abstract}


examined. Thirdly, an integrative approach to destructivity has been proposed. This approach is important because it conceptualizes fragmented parts of destructive patterns, describing them as a unified phenomenon in an integrative fashion.

Keywords: destruction (defeat), distortion, holon, heterogeneity, questionnaires of destruction (defeat), integrative approach.

\section{References}

Abulkhanova, K. A. (2012). Razvitie psikhologii v sisteme kompleksnogo chelovekoznaniya [Development of psychology in the system of the complex science of man] (Pt. 1). Moscow: Institute of Psychology of Russian Academy of Sciences.

Armey, M. F., Schatten, H. T., Haradhvala, N., \& Miller, I. W. (2015). Ecological momentary assessment (EMA) of depression-related phenomena. Review Article. Current Opinion in Psychology, 4, 21-25. doi:10.1016/j.copsyc.2015.01.002

Ashforth, B. E. (1994). Petty tyranny in organizations. Human Relations, 47, 755-778. doi:10.1177/001872679404700701

Baumeister, R. F. (1997). Esteem threat, self-regulatory breakdown, and emotional distress as factors in self-defeating behavior. Review of General Psychology, 1(2), 145-174. doi:10.1037/1089-2680.1.2.145

Baumeister, R. F., \& Scher, S. J. (1988). Self-defeating behavior patterns among normal individuals: Review and analysis of common self-destructive tendencies. Psychological Bulletin, 104(1), 3-22. doi:10.1037/0033-2909.104.1.3

Briones, E., Tabernero, C., \& Arenas, A. (2007). Effects of disposition and self-regulation on selfdefeating behavior. The Journal of Social Psychology, 147(6), 657-680. doi:10.3200/ SOCP.147.6.657-680

Diagnostic and Statistical Manual of Mental Disorders (DSM-III-R). (1987). Washington, DC: American Psychiatric Association.

Dorfman, L. Ya. (1997). Emotsii v iskusstve: teoreticheskie podkhody i empiricheskie issledovaniya [Emotions in art: theoretical approaches and empirical research]. Moscow: Smysl.

Dorfman, L. Ya. (2000). Problema tselogo i chasti v zarubezhnykh sistemnykh issledovaniyakh [The issue of the whole and a part in foreign systems research]. Vestnik Permskogo Gosudarstvennogo Pedagogicheskogo Universiteta. Seriya 1. Psikhologiya, 1-2, 114-122.

Dorfman, L. Ya. (2004). Ya-kontseptsiya: differentsiatsiya i integratsiya [Self-concept: differentiation and integration]. In L. Ya. Dorfman (Ed.), Integral'naya individual'nost', Ya-kontseptsiya, lichnost' [Integral individuality, self-concept, personality] (pp. 96-123). Moscow: Smysl.

Dorfman, L. Ya. (2006). Conception of the metaindividual world: the state of the art. Psychology. Journal of Higher School of Economics, 3(3), 3-34. (in Russian)

Dorfman, L. Ya. (2007). Metaindividual'naya i polimodal'naya modeli kreativnosti [Meta-individual and polymodal models of creativity]. In V. M. Petrov \& A. V. Kharuto (Eds.), Informatsiya, vremya, tvorchestvo [Information, time, creativity] (pp. 73-79). Moscow: Gosudarstvennyi institut iskusstvoznaniya / Moscow Conservatory.

Dorfman, L. Ya. (2012). Empiricheskaya paradigma v psikhologicheskoi nauke [Empirical paradigm in psychological science]. In A. L. Zhuravlev, T. V. Kornilova, \& A. V. Yurevich (Eds.), Paradigmy v 
psikhologii: naukovedcheskii analiz [Paradigms in psychology: science studies analysis] (pp. 335-379). Moscow: Institute of Psychology of Russian Academy of Sciences.

Dorfman, L. Ya. (2014). Kauzal'nyi plyuralizm i psikhologiya (okonchanie) [Causal pluralism and psychology (ending)]. Mir Psikhologii, 4(80), 230-246.

Dorfman, L. Ya. (2016). The causal pluralism and holism in the meta-individual world theory. Psychology. Journal of Higher School of Economics, 13(1), 115-153. (in Russian)

Dorfman, L. Ya., \& Liadov, V. N. (2015). The meta-individual model of discipline (based on cadets at the military university of the Russian Internal Troops). Bulletin of the South Ural State University. Series Psychology, 8(1), 17-28. (in Russian)

Dorfman, L. Ya., \& Tokareva, G. V. (2013). Emotional preferences and the polymodal self-concept of a performing musician. Filologiya i kul'tura. Philology and Culture, 1(31), 235-241. (in Russian)

Dorfman, L. Ya., \& Zlokazov, K. V. (2016a). Defeat and destructive patterns: a brief review of recent studies. Part 1. Bulletin of the South Ural State University. Series Psychology, 9(1), 5-16. (in Russian)

Dorfman, L. Ya., \& Zlokazov, K. V. (2016b). Defeat and destructive patterns: a brief review of recent studies. Part 2. Bulletin of the South Ural State University. Series Psychology, 9(2), 5-13. (in Russian)

Dorfman, L., \& Barashkova, E. (2016). A meta-individual perspective in personality studies. Australian Journal of Education and Science, 1(17), 9, 304313.

Drobysheva-Razumovskaya, L. I., Dorfman, L. Ya., Vyatkin, B. A., Petrov, V. M., \& Zubareva, N. B. (2015). On to integrative perspective in humanities. Integrative Perspective in Humanities, 1, 10-20. (in Russian)

Dunmore, E., Clark, D. M., \& Ehlers, A. (1999). Cognitive factors involved in the onset and maintenance of posttraumatic stress disorder (PTSD) after physical or sexual assault. Behaviour Research and Therapy, 37, 809-829. doi:10.1016/S0005-7967(98)00181-8

Ehlers, A., Maercker, A., \& Boos, A. (2000). Post-traumatic stress disorder following political imprisonment: The role of mental defeat, alienation, and perceived permanent change. Journal of Abnormal Psychology, 109, 45-55. doi:10.1037/0021-843X.109.1.45

Ehlers, A., Clark, D. M., Dunmore, E. B., Jaycox, L., Meadows, E., \& Foa, E. B. (1998). Predicting the response to exposure treatment in PTSD: The role of mental defeat and alienation. Journal of Traumatic Stress, 11, 457-471. doi:10.1023/A:1024448511504

Einarsen, S., Aasland, M. S., \& Skogstad, A. (2007). Destructive leadership behaviour: A definition and conceptual model. Leadership Quarterly, 18, 207-216. doi:10.1016/j.leaqua.2007.03.002

Feeny, N. C., Zoellner, L. A., \& Foa, E. B. (2000). Anger, dissociation, and posttraumatic stress disorder among female assault victims. Journal of Traumatic Stress, 13, 89-100. doi:10.1023/A:1007725015225

Frederick, C. J. (1986). Psychic trauma in victims of crime and terrorism. In G. R. VandenBos \& B. K. Bryant (Eds.), Cataclysms, crises, and catastrophes: Psychology in action (pp. 55-108). Washington, DC: American Psychological Association. doi:10.1037/11106-002

Freud, S. (1965). New introductory lectures on psychoanalysis. New York: Norton. (Original work published 1933).

Fromm, E. (2004). Anatomiya chelovecheskoi destruktivnosti [The anatomy of human destructiveness]. Moscow: AST. (Transl. of: Fromm, E. (1973). The anatomy of human destructiveness. New York: Holt, Rinehart and Winston).

Gilbert, P., \& Allan, S. (1998). The role of defeat and entrapment (arrested flight) in depression: An exploration of an evolutionary view. Psychological Medicine, 28, 585-598. doi:10.1017/S0033291798006710 
Goldstein, R. C., \& Willner, P. (2002). Selfreport measures of defeat and entrapment during a brief depressive mood induction. Cognition and Emotion, 16, 629-642. doi:10.1080/ 02699930143000473

Griffiths, A. W., Wood, A. M., Maltby, J., Taylor, P. J., Panagioti, M., \& Tai, S. (2015). The development of the Short Defeat and Entrapment Scale (SDES). Psychological Assessment. Advance online publication. doi:10.1037/pas0000110

Hawton, K., Rodham, K., Evans, E., \& Weatherall, R. (2002). Deliberate self harm in adolescents: A self-report survey in schools in England. British Medical Journal, 325, 1207-1211. doi:10.1136/bmj.325.7374.1207

Herman, J. L. (1992). Complex PTSD: A syndrome in survivors of prolonged and repeated trauma. Journal of Traumatic Stress, 5, 377-391. doi:10.1002/jts.2490050305

Horowitz, M. J. (1990). A model of mourning: Change in schemas of self and others. Journal of the American Psychoanalytic Association, 38(2), 297-324.

Hyler, S. E., \& Rieder, R. R. (1987). PDQ-R: Personality Diagnostic Questionnaire-Revised. New York: New York State Psychiatric Institute.

Kant, I. (2006). Kritika chistogo razuma [Critique of pure reason]. Moscow: Eksmo. (Transl. of: Kant, I. (1781). Critik der reinen Vernunft [Critique of pure reason]. Riga: Hartknoch. (in Deutsch))

Kelley, K., Byrne, D., Przybyla, D. P. J., Eberly, C., Ebedy, B., Greendlinger, V., ... Gorsky, J. (1985). Chronic self-destructiveness: conceptualization, measurement, and initial validation of the construct. Motivation and Emotion, 9, 135-151. doi:10.1007/BF00991572

Knauss, W. (1999).The creativity of destructive fantasies. Group Analysis, 32, 397-411. doi:10.1177/05333169922076914

Krasikova, D. V., Green, S. G., \& LeBreton, J. M. (2013). Destructive leadership: A theoretical review, integration, and future research agenda. Journal of Management, 39(5), 1308-1338. doi:10.1177/0149206312471388

Lipman-Blumen, J. (2005). Toxic leadership: When grand illusions masquerade as noble visions. Leader to Leader, 36, 29-36. doi:10.1002/1tl.125

Menninger, K. (2001). Voina s samim soboi [Man against himself]. Moscow: EKSMO-Press. (Transl. of: Menninger, K. (1938). Man against Himself. New York: Harcourt, Brace).

Merlin, V. S. (1986). Ocherk integral'nogo issledovaniya individual'nosti [An essay on integral study of individuality]. Moscow: Pedagogika.

Minocha, S., Stonehouse, G., \& Reynolds, M. (2014). Bollywood on creativity: An interview with the internationally acclaimed film director Shekhar Kapur. Journal of Management Inquiry, 23(2), 137-147. doi:10.1177/105649261349982

Morey, L. C. (1988). The categorical representation of personality disorder: A cluster analysis of DSM-III-R personality features. Journal of Abnormal Psychology, 97(3), 314 321. doi:10.1037/0021-843X.97.3.314

Muller, R. T., Sicoli, L. A., \& Lemieux, K. E. (2000). Relationship between attachment style and posttraumatic stress symptomatology among adults who report the experience of childhood abuse. Journal of Traumatic Stress, 13, 321-332. doi:10.1023/A:1007752719557

Petrovsky, V. A. (1981). K ponimaniyu lichnosti v psikhologii [On the understanding of personality in psychology]. Voprosy Psikhologii, 2, 40-46.

Petrovsky, V. A. (1997). Ocherk teorii svobodnoi prichinnosti [An essay on the theory of free causality]. In D. A. Leontiev \& V. G. Shchur (Eds.), Psikhologiya s chelovecheskim litsom: gumanisticheskaya perspektiva v postsovetskoi psikhologii [Psychology with a human face: humanistic perspective in post-soviet psychology] (pp. 124-144). Moscow: Smysl. 
Petrovsky, V. A. (2009). Logika "Ya": personologicheskaya perspektiva [The logic of the Self: a personological perspective]. Samara: Samara State University.

Petrovsky, V. A. (2013). "Ya" v personologicheskoi perspektive [The Self in a personological perspective]. Moscow: HSE Publishing House.

Petrovsky, V. A., \& Starovoitenko, E. B. (2012). The science of personality: Four projects of general personology. Psychology. Journal of Higher School of Economics, 9(1), 21-39. (in Russian)

Reed, G. E., \& Bullis, R. C. (2009).The impact of destructive leadership on senior military officers and civilian employees. Armed Forces and Society, 36(1), 5-18. doi:10.1177/0149206312471388

Reich, J. (1989). Validity of criteria for DSM-III self-defeating personality disorder. Psychiatry Research, 30(2), 145-153. doi:10.1016/0165-1781(89)90156-X

Rubinstein, S. L. (2003). Bytie i soznanie. Chelovek i mir [Being and consciousness. Human and the world]. Saint Petersburg: Piter.

Samuel, D. B., \& Widiger, T. A. (2008). A meta-analytic review of the relationships between the fivefactor model and DSM-IV-TR personality disorders: a facet level analysis. Clinical Psychology Review, 28(8), 1326-1342. doi:10.1016/j.cpr.2008.07.002

Schill, T. (1990). A measure of self-defeating personality. Psychological Reports, 66, 1343-1346. doi:10.2466/pr0.1990.66.3c.1343

Sharp, M., \& Schill, T. (1995). Chronic self-destructiveness and self-defeating personality: Similarities and differences. Journal of Personality Assessment, 64(2), 270-278. doi:10.1207/ s15327752jpa6402_7

Shestakova, E. G. (2011). Agressivnost'v strukture lichnosti: integrativnyi podkhod [Aggressiveness in the structure of personality: an integrative approach] (Ph.D. dissertation, Perm State Institute of Culture, Perm, Russian Federation).

Stamps, J. S. (1980). Holonomy: A human systems theory. Seaside, CA: Intersystems Publications.

Sturman, E. D. (2011). Involuntary subordination and its relation to personality, mood, and submissive behavior. Psychological Assessment, 23, 262-276. doi:10.1037/a0021499

Sturman, E. D., Rose, S., McKeighan, K. M., Burch, J., \& Evanico, K. (2015). Personality and the generation of defeat, involuntary subordination, and depression. Canadian Journal of Behavioural Science, 47, 47-58. doi:10.1037/a0036896

Taussig, H. N., \& Litrownik, A. J. (1997). Self- and Other-directed destructive behaviors: Assessment and relationship to type of abuse. Child Maltreatment, 2(2), 172-182. doi:10.1177/ 1077559597002002010

Taylor, P. J., Gooding, P., Wood, A. M., \& Tarrier, N. (2011). The role of defeat and entrapment in depression, anxiety, and suicide. Psychological Bulletin, 137(3), 391-420. doi:10.1037/a0022935

Taylor, P. J., Wood, A. M., Gooding, P., Johnson, J., \& Tarrier, N. (2009). Are defeat and entrapment best defined as a single construct? Personality and Individual Differences, 47, 795-797. doi:10.1016/j.paid.2009.06.011

Tepper, B. J. (2007). Abusive supervision in work organizations: Review, synthesis, and research agenda. Journal of Management, 33, 261-289. doi:10.1177/0149206307300812

Van der Kolk, B. A., Pelkovich, D., Roth, S., Mandel, F. S., Mcfarlane, A., \& Herman, J. L. (1996). Dissociation, somatization, and affect regulation: The complexity of adaptation to trauma. American Journal of Psychiatry, 153(7 Suppl.), 83-93. doi:10.1176/ajp.153.7.83

Vorontsova, M. V., Makarov, V. E., \& Byundyugova, T. V. (2014). Teoriya destruktivnosti [The theory of destructivity]. Taganrog: Publ. A.N. Stupin. 
Vyatkin, B. A. (Ed.). (2015). Individual'nost' rastushchego cheloveka v usloviyakh sovremennoi shkoly [Individuality of a growing man in conditions of modern school]. Perm: State National Research Polytechnical University of Perm.

Wei, M., \& Ku, T.-Y. (2007). Testing a conceptual model of working through self-defeating patterns. Journal of Counseling Psychology, 54(3), 295-305. doi:10.1037/0022-0167.54.3.295

Yurevich, A. V., \& Ushakov, D. V. (2012). Ekspertnaya otsenka dinamiki psikhologicheskogo sostoyaniya rossiiskogo obshchestva: 1981-2011 gg. [Expert evaluation of the dynamics of psychological state of the Russian society: 1981-2011]. Vestnik Rossiiskoi Akademii Nauk, 82(10), 930-937.

Leonid Ya. Dorfman - head of Psychology and Pedagogy chair, Perm State Institute of Culture, D.Sc.

E-mail: dorfman07@yandex.ru

Kyrill V. Zlokazov - head of Psychology of activity special field and Pedagogy chair, Ural Institute of Law, Ph.D.

E-mail: zkirvit@yandex.ru 